\title{
Article \\ Comparison of Mechanical and Physicochemical Characteristics of Potato Starch and Gelatine Blend Bioplastics Made with Gelatines from Different Sources
}

\author{
Marta Mroczkowska ${ }^{1}$, David Culliton ${ }^{2}$, Kieran Germaine ${ }^{1}$ and Adriana Neves ${ }^{1, *(1)}$ \\ 1 Department of Science and Health, Institute of Technology Carlow, R93 V960 Carlow, Ireland; \\ marta.mroczkowska@itcarlow.ie (M.M.); kieran.germaine@itcarlow.ie (K.G.) \\ 2 Department of Aerospace, Mechanical and Electronic Engineering, Institute of Technology Carlow, \\ R93 V960 Carlow, Ireland; David.Culliton@itcarlow.ie \\ * Correspondence: nevesa@itcarlow.ie
}

check for updates

Citation: Mroczkowska, M.; Culliton,

D.; Germaine, K.; Neves, A.

Comparison of Mechanical and

Physicochemical Characteristics of

Potato Starch and Gelatine Blend

Bioplastics Made with Gelatines from

Different Sources. Clean Technol. 2021,

3, 424-436. https://doi.org/

10.3390/cleantechnol3020024

Academic Editor: Dmitry Yu. Murzin

Received: 22 February 2021

Accepted: 20 April 2021

Published: 11 May 2021

Publisher's Note: MDPI stays neutral with regard to jurisdictional claims in published maps and institutional affiliations.

Copyright: (c) 2021 by the authors. Licensee MDPI, Basel, Switzerland. This article is an open access article distributed under the terms and conditions of the Creative Commons Attribution (CC BY) license (https:// creativecommons.org/licenses/by/ $4.0 /)$.

\begin{abstract}
Environmentally friendly packaging is becoming more popular as the number of companies implementing more sustainable solutions continues to increase, and consumers become more aware and choose more environmentally friendly options. However, not all environmentally friendly packaging meets all desirable properties, as some are only partially made of renewable raw materials or degrade over a long period of time. Bioplastics constructed from blends of gelatine and starch are solely made from renewable raw materials. Combined with relatively short degradation times, these materials have the potential to replace currently used, non-biodegradable film and single-use plastics. However, despite these advantages, further research is required to identify the best combination of raw materials, selectively and collectively, and to then optimise the appropriate physicochemical properties of the resultant bioplastics. In this study, gelatine from different sources (piscine, porcine, bovine) combined with potato starch was used to generate home-compostable bioplastics. These bioplastics were assessed in terms of water solubility, water content, opacity, surface roughness, and key mechanical properties such as tensile strength. Significant differences were found, particularly for piscine gelatine blends. It was concluded that piscine gelatine is a promising protein with highly relevant properties for the bioplastics industry.
\end{abstract}

Keywords: bioplastics; gelatine; piscine gelatine; porcine gelatine; bovine gelatine; gelatine-starch blend

\section{Introduction}

Single-use plastics are a serious environmental threat. They consume vital resources (it takes three times the amount of water to produce a plastic bottle than it does to fill one), and destroy picturesque landscapes, release toxic chemicals, and enter the food chain in the form of microplastics [1]. Synthetic and semi-synthetic plastic polymers are strong, durable, lightweight, and low cost. As a result, they have applications in a variety of industries, primarily packaging, which represents the shortest product lifetime [2]. Alternatives to fossil fuel-based plastics are gaining popularity due to changing consumer habits, which are driven by necessary policy changes, including the European Union's Plastic Strategy. This strategy outlines the long-term plan to ban single-use plastics by 2030 [3]. Bioplastics are regarded as promising alternatives for many of these detrimental applications [4].

Bioplastic can be classified into two groups: biodegradable and non-biodegradable. Polyethylene terephthalate (PET) and polyethylene (PE) are widely used petroleum-based plastics. Recent research findings show the possibility of producing these from natural resources such as sugarcane. Although bio-PET and bio-PE are derived from biomass and their carbon footprint is reduced, they resemble their petrochemical versions in that they are also non-biodegradable [5]. Biodegradable plastics include polylactic acid (PLA), polyhydroxyalkanoates (PHA), cellulose, and starch blends, but biodegradation conditions and 
rates range greatly. PLA is biodegradable but only in certain conditions and temperatures over $50{ }^{\circ} \mathrm{C}$, meaning it is not home compostable and non-biodegradable in soil and aquatic environments [6].

Sustainable raw materials that are commonly used in the bioplastics industry include proteins, starch, and other food-related substances. Enormous volumes of food waste are generated by the food industry, which is rich in these substances. These can be valuable materials for other industries. Thus, new waste management methods based on industrial symbiosis initiatives are becoming more popular among food producers, in order to fully exhaust the potential of these by-products [7]. A total of 171 million tonnes of fish were produced worldwide in 2016. Consequently, large amounts of fish waste are generated, which ranges from $30-85 \%$ of total catch weight (depending on the species), which is discarded or used as low-value animal feed [8]. From this rich-in-collagen waste (bones, skin), gelatine can be extracted and used as a base for a novel range of bioplastics. Piscine gelatine became of interest due to drawbacks of porcine and bovine gelatines, which are associated with diseases such as foot-and-mouth and bovine spongiform encephalopathy (BSE) $[9,10]$.

When collagen is partially hydrolysed a functional protein called gelatine is generated, which is known for its film-forming properties. Blends of gelatine and starch are used in the bioplastic industry to generate films with improved polymeric matrix [11]. These biomass-based films have major downfalls, as current processing technologies are not suitable, and although blends have improved characteristics, structural and functional properties still require improvement. Although starch-based polymers possess moderate properties, in 2019, 21.3\% of all bioplastic produced worldwide was starch based, showing an increasing demand for cheap, renewable, biomass-based packaging alternatives [5].

A research study reported by Fakhouri et al. (2012) [4], investigated the influence of different types of plasticizer on gelatine-starch blends. Conclusions were made that tensile strength and elongation at break are influenced by type of plasticiser, but these properties are dependent on number of other variables such as protein and starch concentrations as well as the thickness of the bioplastic. In another study by Fakhouri et al. (2013) [11], which investigated different processing methods of gelatine-starch blend bioplastic, they concluded that bioplastic generated by casting had lower thickness, opacity, and water vapor permeability and had higher tensile strength than bioplastic generated by pressing or blowing. A study by Podshivalor et al. (2017) investigated the correlation between morphology and the physical properties of a gelatine-starch blend. One of the conclusions was that glycerol, which is primary used as plasticizer, is also a compatibilizer in bioplastic formulation. None of these studies pointed to which formulation is the best, but did provide data for better understanding, based on which formulations of bioplastic can be chosen to produce bioplastic for specific purpose. This paper adds to the knowledge and understanding of the correlation between gelatine source and physicochemical properties of gelatine-starch blends.

To determine the influence of the source of gelatine on functional and structural properties of gelatine starch blend bioplastic, the objectives of this study were (a) to generate bioplastics using potato starch and gelatine from three different sources (piscine, porcine, and bovine), (b) to characterise the physiochemical properties of the bioplastics generated, and (c) to compare and contrast the generated bioplastics.

\section{Materials and Methods}

\subsection{Materials}

Potato starch (MP BIomedicals LLC, Amsterdam, The Netherlands), 200 bloom foodgrade piscine gelatine (Louis Francois, Croissy-Beaubourg, France), 130 bloom porcine gelatine (ACROS Organics, Vantaa, Finland), and 250 bloom bovine gelatine (VWR Chemicals, VWR International, Radnor, PA, USA) were used to generate bioplastics. Glycerol (EMPROVE ${ }^{\circledR}$ bio, Merck KGaA, Darmstadt, Germany) was used as plasticiser. HPLCgrade acetonitrile (VWR Chemicals, VWR International, Radnor, PA, USA), HPLC-grade 
water (VWR Chemicals, VWR International, Radnor, PA, USA), and trifluoroacetic acid (Fisher Chemicals, Loughborough, UK) was used in the HPLC analysis. Individual blends of gelatines and starches used to make bioplastics have been widely reported in literature $[4,11,12]$. However, to the best of our knowledge, no comparative studies investigating a range of different types of gelatine/starch blends have been reported.

\subsection{Bioplastics Preparation}

The reported initial compositions of the generated biopolymers were based on a number of blind tests, which were performed as a precedent to subsequent compositional definitions. These blind tests entailed testing visual factors such as viscosity of the mixture for easiness of working, setting, and drying time of the polymer and plastic-like appearance when changing the conditions of work. The factors changed were temperature at the time of processing the mixture, the order of adding each component of the mixture, and the speed and method of mixing. Initial investigations centred on creating a general understanding of the synergistic/antagonistic interaction between the various compositional elements. These ingredients were selected based on a systematic analysis of the polymerisation process combined with the marine waste-stream target as a primary source of collagen. This was followed by a general Box-Behnken design of experiments approach in Excel 2016 (Microsoft Excel 2016 MSO, San Francisco, CA, USA), which was devised and implemented based on previously identified factors in the initial blind tests. The key parameters determined were glycerol concentration, gelatine concentration, and starch concentration, based on the outputs and analysis of this preliminary work. The preliminary work that led to the settings reported in this paper was presented by Mroczkowska et al. (2019) [13] and Eyre et al. (2019) [14]. In a beaker, $10 \mathrm{~g}$ of gelatine were hydrated in $70 \mathrm{~mL}$ of tap water, and heated up to $50{ }^{\circ} \mathrm{C}$ while continuously stirring until the gelatine was fully dissolved. In another beaker, a solution with $5 \mathrm{~g}$ of potato starch, $7.5 \mathrm{~mL}$ of glycerol, and $30 \mathrm{~mL}$ of tap water was prepared and combined with the dissolved gelatine solution, then heated up to $75-80{ }^{\circ} \mathrm{C}$ and stirred until a homogenous solution was obtained and all ingredients were dissolved. The bioplastics solution was poured onto a silicon tray $(245 \mathrm{~mm} \times 245 \mathrm{~mm})$ and air dried for $48 \mathrm{~h}$ in a well-ventilated place. After this time the bioplastic was removed from the tray and was ready to be used for further analysis.

\subsection{Water Solubility}

The method proposed by Gontard et al. (1992) [15] was used with some modifications to determine the water solubility of the bioplastic samples. Samples of $2 \mathrm{~cm}$ circular discs of each bioplastic were dried for $24 \mathrm{~h}$ at $105^{\circ} \mathrm{C}$, weighed, and recorded as initial weight, then immersed in $50 \mathrm{~mL}$ of deionized water for $24 \mathrm{~h}$ under moderated aggregation (120 rpms). After this time, the bioplastic was removed and placed in the oven for another $24 \mathrm{~h}$ at $105^{\circ} \mathrm{C}$ to dry. The final weight was recorded and the following formula was used to calculate the percentage of weight loss:

$$
\text { (Initial Weight }- \text { Final Weigh/Initial Weight }) \times 100
$$

\subsection{Water Content}

The water content of the bioplastic samples was determined gravimetrically. Samples of $2 \mathrm{~cm}$ circular discs were weighted, dried at $105^{\circ} \mathrm{C}$ for $24 \mathrm{~h}$, and weighed again. The water content was determined by calculating the weight loss and expressed in percentage.

\subsection{Roughness}

A SURFCOM130A roughness tester with a TS100 roughness tester sensor was calibrated with a standard of $\mathrm{Ra}=1.54 \mu \mathrm{m}$ before measuring the roughness of the bioplastic. To perform the roughness measurements the bioplastic sample was laid flat under the sensor needle, which was then adjusted to just lightly touch the bioplastic surface. When the sensor needle was in place the start button was pressed and the needle automatically 
moved across the sample, taking measurements of the surface roughness. The analysis was preformed four times on each sample and an average was used in further analysis.

\subsection{Opacity and Colour}

The colorimeter from PCE Instruments (Meschede, Germany) was used to measure the opacity and colour of the bioplastic. The colorimeter was calibrated with a standard black-and-white background. The measurements were taken by placing the colorimeter's sensor head on a sample with a black or white background and pressing the start button, which was repeated five times for each sample. The following values were recorded by the colorimeter: $\mathrm{L}^{*}=$ brightness, $\mathrm{a}^{*}$ from green $(-)$ to red $(+)$, and $\mathrm{b}^{*}$ from blue (-) to yellow $(+)$. Values of $a^{*}$ and $b^{*}$ were plotted to visualise the data and opacity was calculated using the following equation used by Fakhouri et al. (2013) [11], with some modifications:

$\mathrm{L}_{\mathrm{p}}=\mathrm{L}_{\mathrm{pN}} / \mathrm{L}_{\mathrm{pB}} \times 100100-\mathrm{L}_{\mathrm{p}}=\mathrm{O}_{\mathrm{p}}$

where the terms are defined as following:

$\mathrm{L}_{\mathrm{p}}=$ brightness of the bioplastics $(\%)$

$\mathrm{O}_{\mathrm{p}}=$ opacity of the bioplastics (\%)

$\mathrm{L}_{\mathrm{pN}}=$ brightness of the bioplastics overlaid with a black background

$\mathrm{L}_{\mathrm{pB}}=$ brightness of the bioplastics overlaid with a white background

\subsection{Fourier-Transform Infrared Spectroscopy (FTIR)}

A Spectrum 65 FT-IR Spectrometer (Perkin Elmer, Massachusetts, USA) was used to analyse the bioplastic samples. The analysis was performed by placing the sample on the FTIR sensor. Then the analysis was initiated, which emitted infrared light and measure the frequencies at which the infrared light was absorbed by the sample. The results were recorded as \% transmission.

\subsection{Tensile Strength and Elongation}

Ultimate tensile strength was determined using a $5 \mathrm{~T}$ Tensile Tester by Haida International with a test speed of $50 \mathrm{~mm} / \mathrm{min}$. The bioplastic samples were cut using a metal scalpel into a dog-bone shape and the edges where the grips held the sample was layered with an additional layer of bioplastic on each side to improve the grip. The test sample was placed into the grips and set into position before the test was initiated. Each sample was stretched until the sample broke in half. The ultimate tensile strength was determined as the highest tensile strength recorded and elongation at break was determined at the point of rupture. The following formula was used to calculate the ultimate tensile strength:

$$
I f_{T S}=F_{\max } / A_{0}
$$

where: $I f_{T S}=$ tensile strength, $F_{\max }=$ maximum force, and $A_{0}=$ initial surface width.

\subsection{RP-HPLC}

Three gelatines from different sources (piscine, porcine, and bovine) were analysed using RP- HPLC. The gelatines were suspended in HPLC-grade water at $0.8 \%(w / v)$. HPLC analysis was performed on a C18 column guarded by a C18 guard column and coupled to an RP-HPLC system. HPLC-grade water with trifluoroacetic acid (TFA) $0.1(v / v)$ was used as mobile phase A and $80 \%(v / v)$ acetonitrile was used as mobile phase B. The analysis was carried out at a flow rate of $1.0 \mathrm{~mL} \mathrm{~min}^{-1}$ with a linear gradient of phase $\mathrm{B}$ from $0 \%$ to $100 \%$ over $30 \mathrm{~min}$. The sample size was $10 \mu \mathrm{L}$, and the absorbance of the elute was measured at $218 \mathrm{~nm}$ and $280 \mathrm{~nm}$.

\subsection{Statistical Analysis of Data}

Statistical analysis was done using one-way analysis of variance (ANOVA), and where appropriate, Tukey-Kramer analysis was used. The significance level was $p \leq 0.05$. 
The software used to carry out the analysis was SPSS Statistics (IBM SPSS Statistics 2015, New York, NY, USA) and Excel 2016 (Microsoft Excel 2016 MSO, San Francisco, CA, USA).

\section{Results and Discussion}

\subsection{Bioplastics Preparation}

Bioplastic blends comprising different gelatines and potato starch were generated (Figure 1). Visual differences in the appearance of the bioplastic films were observed, and the mechanical and physicochemical properties of the bioplastics were investigated. Apart from the source of the gelatine, the compositional amounts for all other elements were consistent for all bioplastics. Observed differences were consequently attributed to the gelatine source.

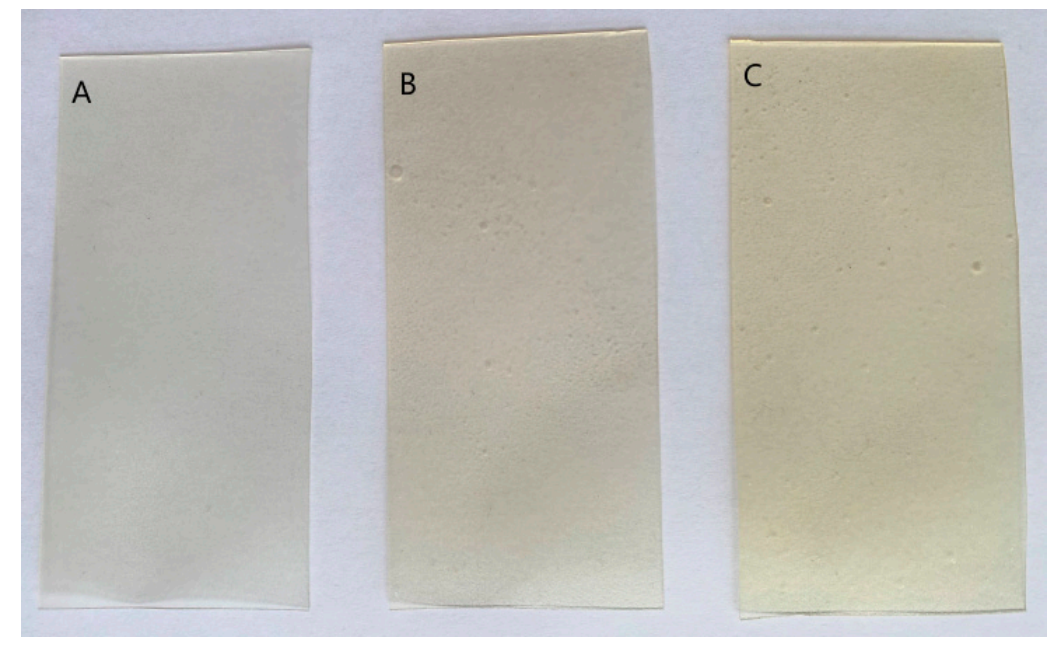

Figure 1. Bioplastic generated from potato starch and different gelatines. (A) piscine gelatine, (B) porcine gelatine, and $(\mathbf{C})$ bovine gelatine.

\subsection{Water Solubility}

Water solubility is one of the most important bioplastic characteristics in relation to gelatine and starch, as it can determine the potential application for the bioplastics. The bioplastics generated in this study were fully water soluble but could substantially delay the onset of full aqueous disassembly. Bioplastics made with piscine gelatine lost significantly less weight, at $38 \pm 0.003 \%$ over $24 \mathrm{~h}$ in water, compared to bioplastics made with porcine $(41 \pm 0.009 \%)$ or bovine gelatine ( $48 \pm 2.8 \%$ ) (Figure 2$)$. This is an advantage of piscine gelatine, as withstanding degradation from water is important when it comes to applications. Previous studies showed a relationship between water solubility of starch blend bioplastics and starch concentration. Increased starch concentration resulted in increased solubility, whereas glycerol concentration showed no effect on solubility $[16,17]$. A solubility of bioplastics generated with potato starch and sodium alginate was reported at around 60\% [17]. This result is not significantly different than the result obtained with the potato and bovine gelatine blend; however, it is significantly different than the one generated with potato and piscine gelatine [18-20]. 


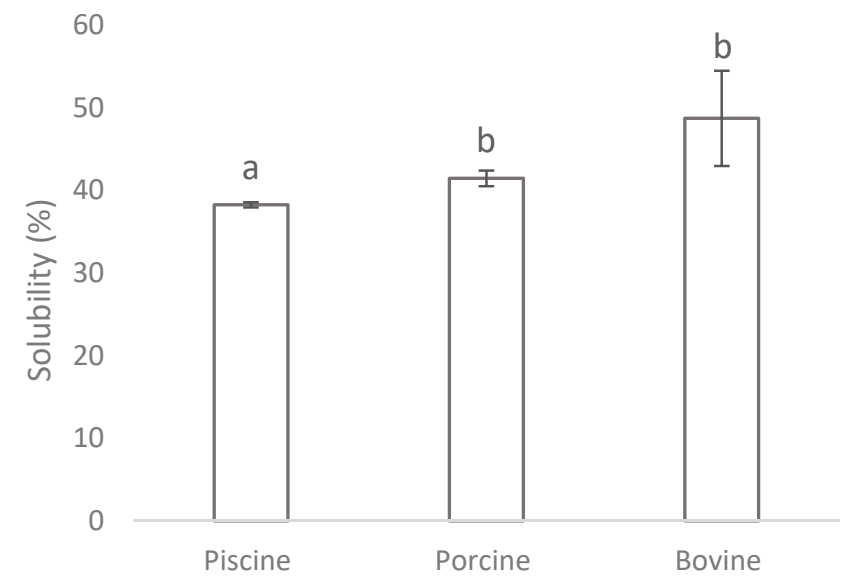

Figure 2. Solubility in water of bioplastics generated from porcine, piscine, and bovine gelatine. Values represent an average of $n=3$; error bars represent standard deviation with different lowercase letters representing significantly different values.

\subsection{Moisture Content}

There was no statistically significant difference between the moisture content in any of the synthesised bioplastics. The measured contents ranged from $15 \pm 0.3 \%$ to $17 \pm 4.3 \%$ (Figure 3). Aspects that influence moisture content include hydrophobicity, plasticiser concentration, and starch-to-gelatine ratio. Bioplastics made from a blend of gelatine and starch typically cannot be completely dried, since water acts as a plasticiser along with glycerol and provides elasticity to the material [21,22]. The moisture content of gelatine and potato starch has been reported previously, ranging from 15 to 18\% [12]. However, no study compared different gelatines and their moisture content in gelatine-starch blend bioplastic.

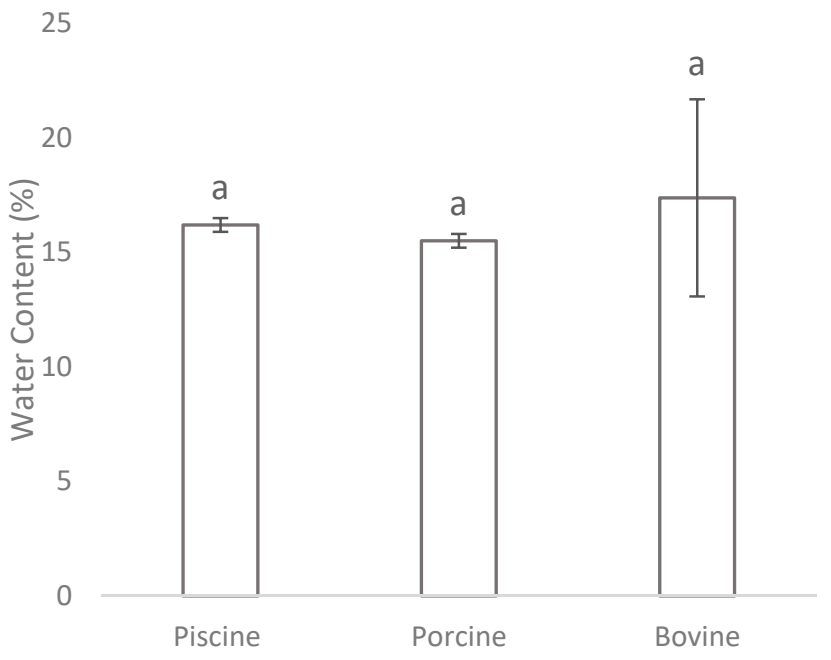

Figure 3. Water content of bioplastics generated from porcine, piscine, and bovine gelatine. Values represent an average of $n=3$; error bars represent standard deviation with different lowercase letters representing significantly different values.

\subsection{Surface Roughness}

The measured surface roughness of the bioplastics yielded significant differences, depending on the composition (Figure 4). Bioplastics generated with piscine gelatine were significantly rougher, with $R_{a}$ of $4.5 \pm 0.25 \mu \mathrm{m}$, compared to bioplastics generated with bovine gelatine, with $R_{a}$ of $3.04 \pm 0.14 \mu \mathrm{m}$, whereas porcine gelatine blends lay in between these two ranges, with an $R_{a}$ of $3.7 \pm 0.31 \mu \mathrm{m}$. Other studies have shown that by using other approaches such as SEM imaging, starch blend bioplastics have different roughness depending on their formulation, such as that described by Amin et al. (2019). However, to 
date no other publication has shown the differences in roughness on piscine- vs. bovinevs. porcine-based gelatines [23]. The higher surface roughness of the piscine, and to a lesser extend the porcine, blends can be an advantage for single-use product ranges such as plastic bags, which require labels to be ink-printed directly onto the packaging. Previous studies showed similar surface roughness $(3.55 \pm 0.33 \mu \mathrm{m})$ for potato starch and sodium alginate blend bioplastic [19].

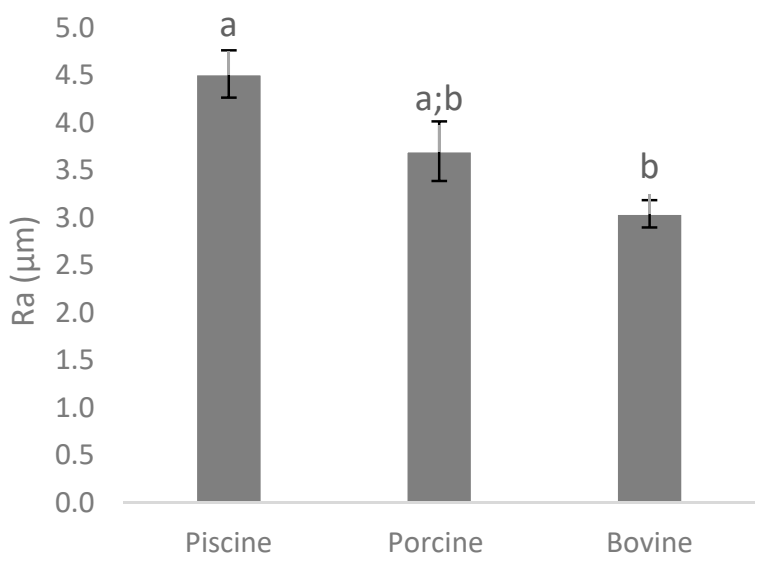

Figure 4. Roughness values of bioplastic surfaces generated from porcine, piscine, and bovine gelatine. Values represent an average of $n=3$; error bars represent standard deviation with different lowercase letters representing significantly different values.

\subsection{Opacity and Colour}

Opacity can be a critical characteristic of a material when it is used for food packaging, as many foods on the market come in clear packaging, whereas many of the bioplastics produced from starch and gelatine blends tend to be yellowish in colour [24]. Bioplastics made with piscine gelatine are significantly less opaque, at $22.3 \pm 1.8 \%$ (Figure 5), than ones made with porcine gelatine, at $25.7 \pm 1.3 \%$, or bovine gelatine at $24.7 \pm 0.5 \%$. This is an advantage of piscine gelatine, since, as mentioned before, clear packaging is desirable.

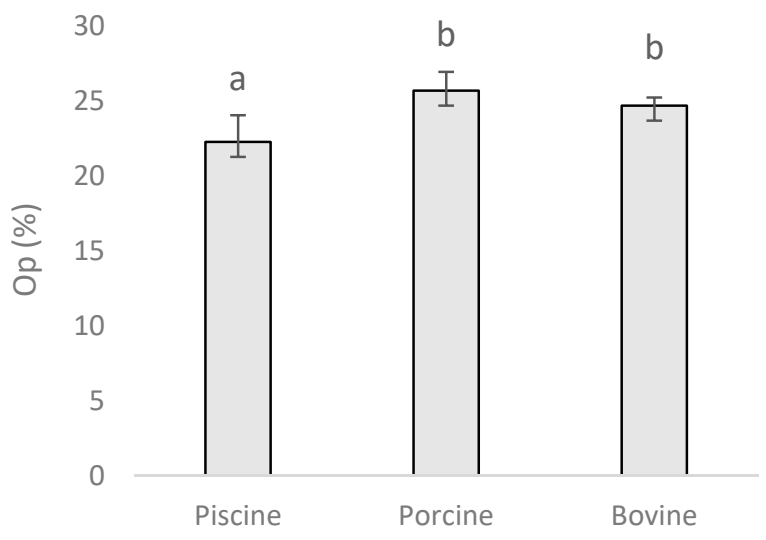

Figure 5. Opacity of bioplastics generated from piscine, porcine, and bovine gelatines. Values represent an average of $n=3$; error bars represent standard deviation with lowercase letters representing significantly different values.

Bioplastics made from blends of starch and gelatine are naturally yellow in colour due to the colour of the incorporated gelatine. Differences in the gelatine colour of the different sources were noted during macroscopic examination. As a result, bioplastics made from these different gelatines were similarly found to vary in this yellow intensity (Figure 1). Colorimetric assessment of the bioplastics (Figure 6) demonstrated that bioplastic generated with piscine gelatine was less yellow in colour compared to the other 
gelatines. However, according to the colorimeter manual, all of these were considered to be white in colour. The opacity of bioplastic films made from corn starch and gelatine has been reported in the literature to range from 1 to $90 \%$ [11]. The opacity of bioplastic films relays heavily on component origins and film thickness [25], therefore these results cannot be directly compared.

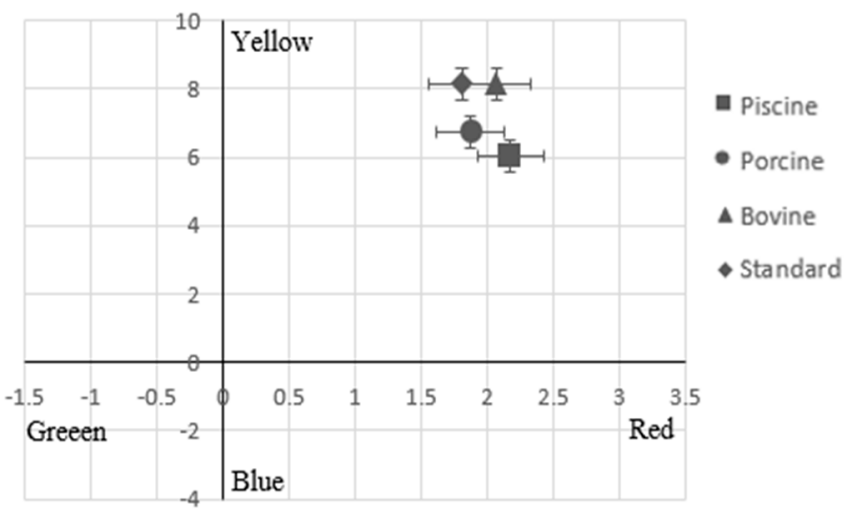

Figure 6. Colour $\mathrm{a}^{*}, \mathrm{~b}^{*}$ values of the bioplastics generated with piscine, porcine, and bovine gelatine and potato starch. Values represent an average of $n=3$; error bars represent standard deviation.

\subsection{FTIR}

The FTIR analysis was conducted to identify and compare different bonds created in the bioplastic blends of different gelatines and starch. Figure 7 shows the spectrums of all three types of bioplastics generated in the study. The FTIR analysis of bioplastics derived from fish, porcine, and bovine gelatine showed identical FTIR spectra for all three types of bioplastics, meaning that although they differed in structure, they all had the same chemical composition regardless of the gelatine source. An $\mathrm{O}-\mathrm{H}$ stretch was observed in the $3500-3000 \mathrm{~cm}^{-1}$ regions, a C $-\mathrm{H}$ stretch at $2910 \mathrm{~cm}^{-1}$, a C $=\mathrm{O}$ stretch at $1600 \mathrm{~cm}^{-1}$, and a C-O-H stretch at $990 \mathrm{~cm}^{-1}$. The FTIR spectrum of sweet potato and corn starch was been reported in literature with peaks in the same regions $[23,26]$. Additional peaks were noted from this study as being attributed to gelatine. However, although all bioplastics have the same chemical composition, they have different physiochemical properties that are the result of the gelatine source.

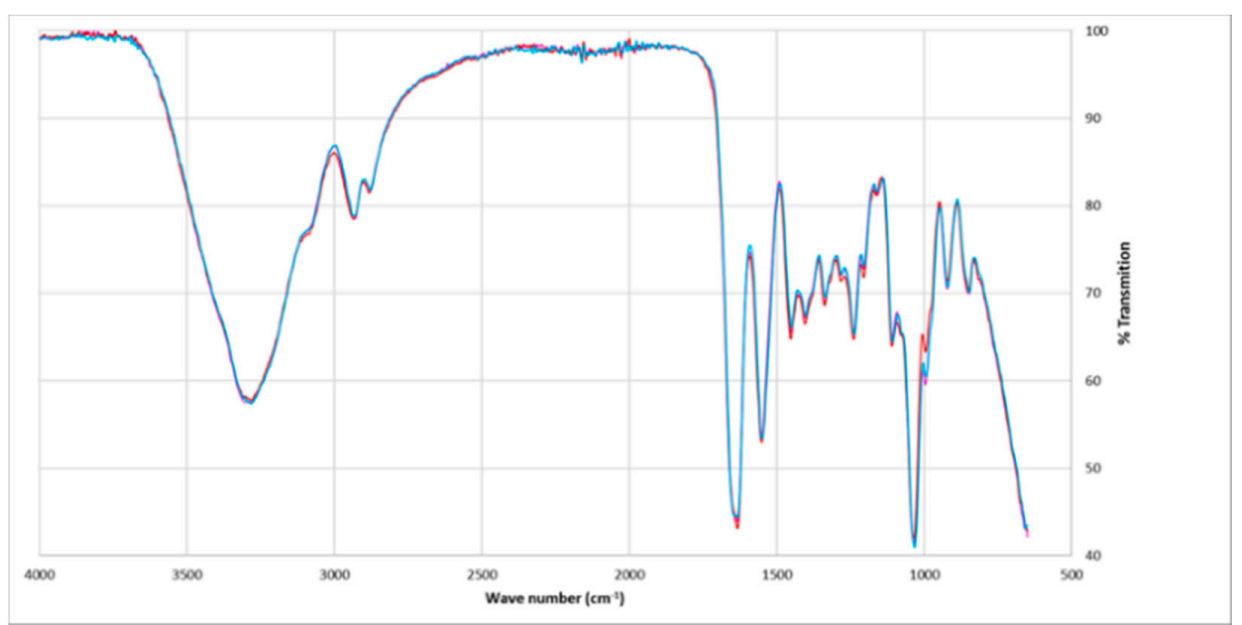

Figure 7. Fourier transform infrared (FTIR) spectra of the bioplastics generated with piscine, porcine, and bovine gelatine and potato starch. 


\subsection{Tensile Strength and Elongation}

In many applications, the ultimate tensile strength of a plastic is critical [27]. In the current study the bioplastics underwent tensile testing on a $50 \mathrm{kN}$-rated dual-column universal testing machine using a $1 \mathrm{kN}$ load cell and a strain rate of $50 \mathrm{~mm} / \mathrm{min}$. The fish gelatine bioplastic exhibited the highest tensile strength, at $8.1 \pm 0.68 \mathrm{MPa}$. This was significantly higher than the tensile strength demonstrated by the porcine- or bovine- gelatine bioplastics, at $4 \pm 0.41 \mathrm{MPa}$ and $3.6 \pm 0.39 \mathrm{MPa}$, respectively. In comparison, low density polyethylene (LDPE), which is used extensively for packaging and bags, has an ultimate tensile strength of 8-58 MPa [10], which statistically places the piscine blend within this range. The tensile strength of the bioplastics is influenced by the plasticiser concentration. The higher the plasticiser concentration, the lower the tensile strength [20,25-27]. In a study by Santana et al. [18] on starch-based bioplastic from jackfruit, the highest tensile strength reported was $3.12 \mathrm{MPa}$, which is significantly lower than results obtained in this study, demonstrating an improvement in TS through the incorporation of fish gelatine in bioplastic formulation [18].

Elongation at break is the maximum length of the bioplastic before rupture. It is the ability of a material to resist change in shape when subjected to force [28]. The elongation at break ranged from 84 to $114 \%$, (Table 1) with piscine gelatine having the highest elongation at break, correlating with the highest tensile strength. The values of elongation were significantly higher than those reported by Sofiah et al. (2019) [27], who reported on the elongation of starch bioplastic. Elongation and tensile strength are strongly influenced by plasticiser content. A higher plasticiser content results in an increase in viscoelasticity, giving more mobility for polymer chains. Therefore, tensile strength and elongation can be easily modified by adjusting the plasticiser content. The higher the plasticiser concentration, the lower the tensile strength and the higher the elongation [29-31]. Figure 8 shows the elongation at break. Piscine gelatine ruptured more rapidly than porcine or bovine gelatine, which can be seen in the graphs below. This can be attributed to the higher force that was applied to the piscine gelatine bioplastic before it ruptured.

\subsection{RP-HPLC}

Gelatines from three different sources (piscine, porcine, and bovine) were analysed by RP-HPLC and their spectrums were compared. All spectrums had peaks with similar retention times, suggesting almost identical chemical composition. Although their retention times were very similar, the peak shapes varied from sample to sample, with the piscine spectrum (Figure 9) having one uniform peak, the porcine spectrum (Figure 10) having three overlapping peaks, and the bovine spectrum (Figure 11) having two overlapping peaks. These differences in spectrum peaks suggest structural differences between the different gelatines. The RP-HPLC spectrum results are comparable to spectra of intact gelatine extracts reported in the literature, with some minor variations [32].

Table 1. Ultimate tensile strength (MPa) and elongation at break (\%) of bioplastic generated with different gelatines $(n=4)$.

\begin{tabular}{ccc}
\hline Gelatine & Ultimate Tensile Strength (MPa) & Elongation at Break (\%) \\
\hline Piscine & $8.10^{*}( \pm 0.68)$ & $114 \%$ \\
Porcine & $4.00( \pm 0.41)$ & $84 \%$ \\
Bovine & $3.60( \pm 0.39)$ & $98 \%$ \\
\hline
\end{tabular}

\footnotetext{
* = statistically significantly different.
} 

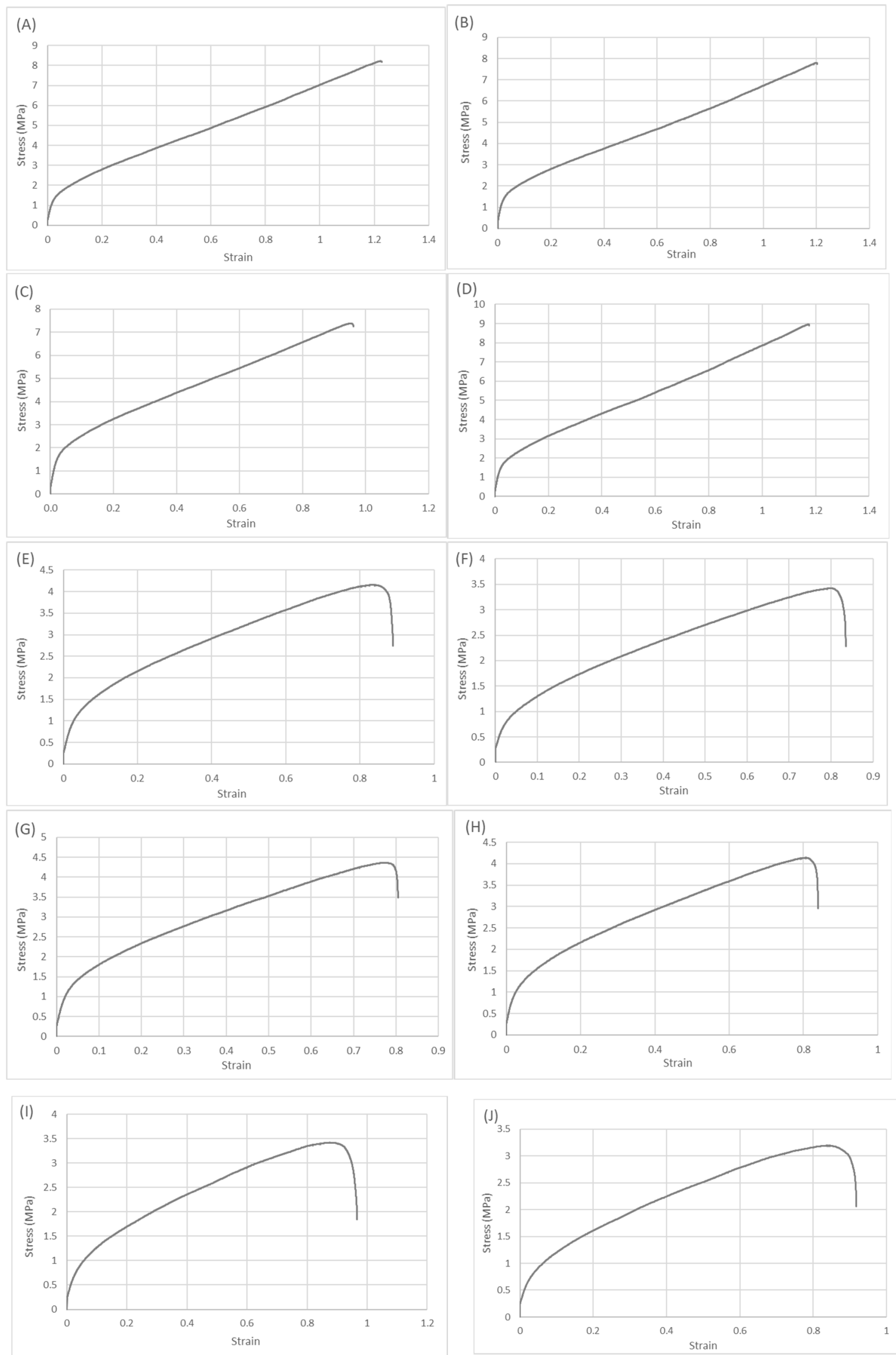

Figure 8. Cont. 

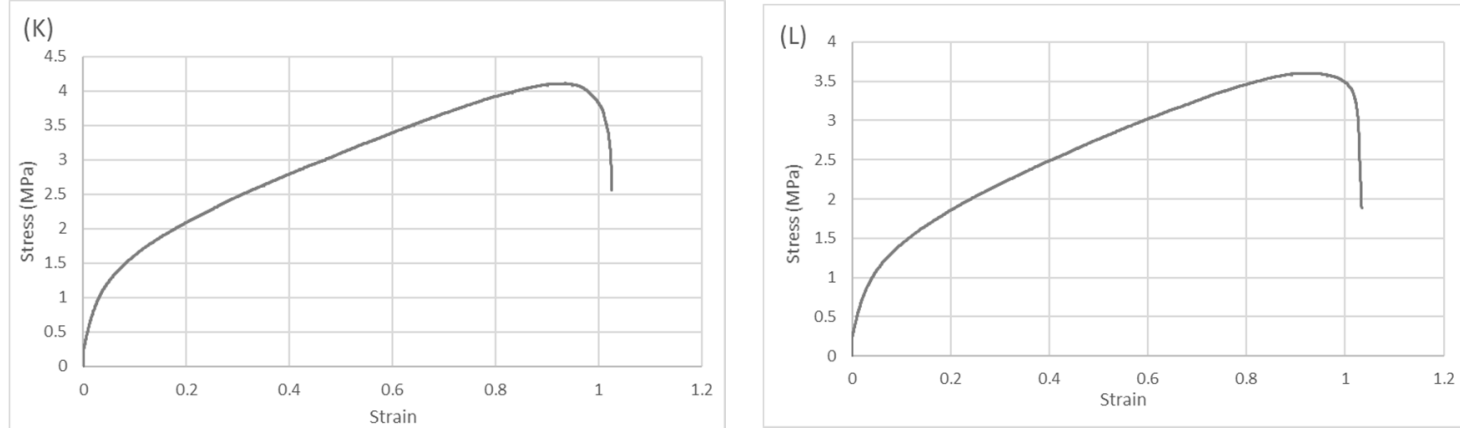

Figure 8. Stress over strain graphs. $(\mathbf{A}-\mathbf{D})=$ replicates of piscine gelatine bioplastic, $(\mathbf{E}-\mathbf{H})=$ replicates of porcine gelatine bioplastic, $(\mathbf{I}-\mathbf{L})=$ replicates of bovine gelatine bioplastic.

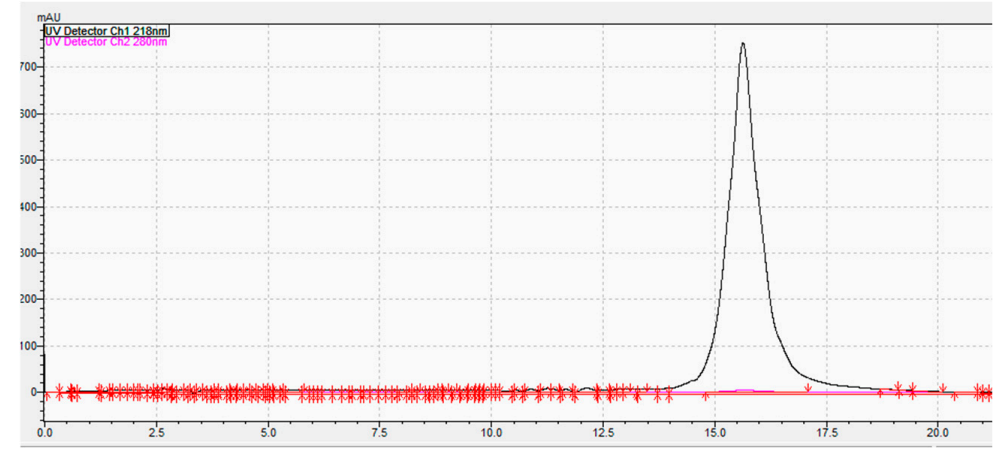

Figure 9. Reverse phase high-performance liquid chromatography (RP-HPLC) spectrum of piscine gelatine.

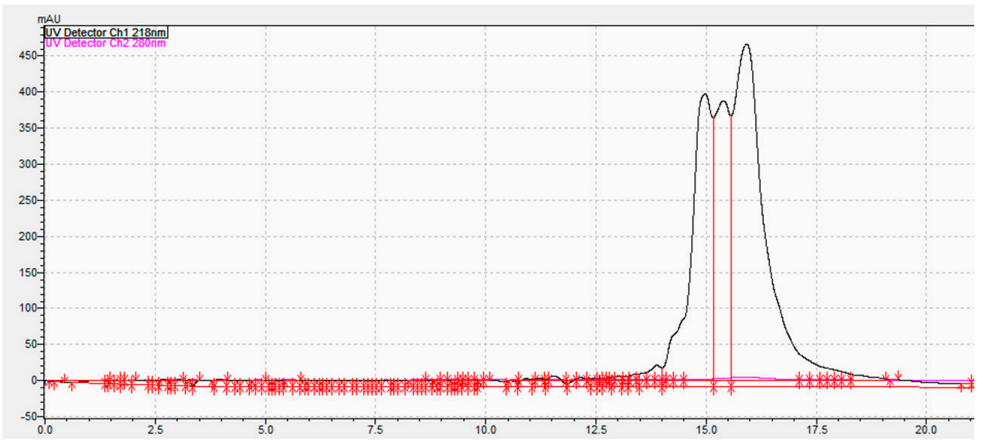

Figure 10. Reverse phase high-performance liquid chromatography (RP-HPLC) spectrum of porcine gelatine.

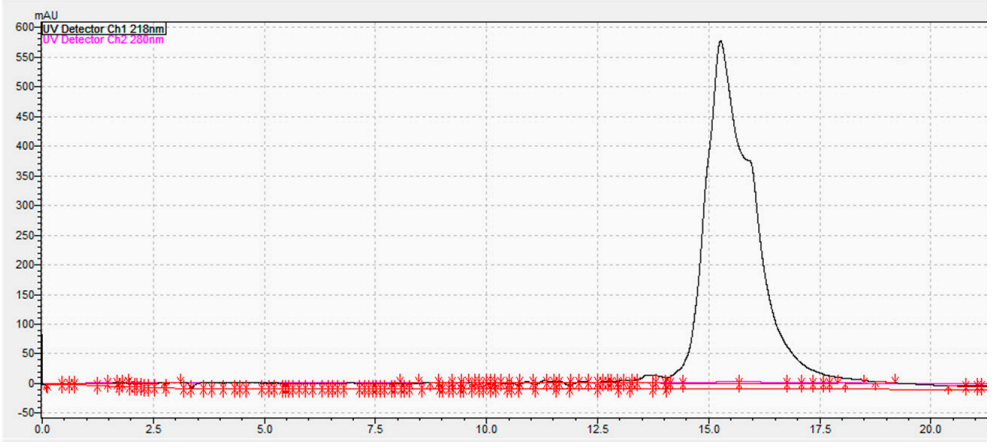

Figure 11. Reverse phase high-performance liquid chromatography (RP-HPLC) spectrum of bovine gelatine. 


\section{Conclusions}

Overall, significant differences in some characteristics were noted between the synthesised bioplastics. These differences can be attributed to different gelatine sources. The FTIR results displayed identical spectra for all three types of bioplastics generated, but the RPHPLC spectra of the gelatines showed that they had very different structures. These results suggest that the differences in bioplastic characteristics are due to structural differences between gelatines from different sources, as the concentration of starch and glycerol was uniform for all samples. Depending on the purpose the bioplastic is used for, different gelatine sources may be more suitable. Out of all three bioplastics, piscine gelatine generated the most durable bioplastics in contact with water, staying fully water soluble. The implication is that piscine bioplastic will maintain its functional integrity whilst in use but will undergo disintegration during the composting process. All results of the characteristics assessed in the present study show that piscine gelatine possesses unique properties that can benefit bioplastic applications. This study shows that there is an important link between the source of the gelatine and the characteristics of bioplastics generated. By understanding the influence of the gelatine source, it is possible to develop bioplastics with improved physio-chemical characteristics at a low cost and with environmentally friendly methods.

Author Contributions: Conceptualization, A.N.; methodology, A.N. and D.C.; investigation, M.M.; writing - original draft preparation, M.M.; writing—review and editing, A.N., D.C., and K.G.; supervision, A.N., D.C., and K.G.; project administration, M.M., A.N., D.C., and K.G.; funding acquisition, A.N. All authors have read and agreed to the published version of the manuscript.

Funding: This research was funded by Institute of Technology Carlow President Award Fellowship grant number PES1300 and the APC was funded by Institute of Technology Carlow.

Institutional Review Board Statement: Not applicable.

Informed Consent Statement: Not applicable.

Data Availability Statement: Data is contained within the article.

Conflicts of Interest: The authors declare no conflict of interest.

\section{References}

1. Adamcová, D.; Elbl, J.; Zloch, J.; Vaverková, M.D.; Kintl, A.; Juřrčka, D.; Hladký, J.; Brtnický, M. Study on the (bio)degradation Process of Bioplastic Materials under Industrial Composting Conditions. Acta Univ. Agric. Silvic. Mendel. Brun. 2017, 65, 791-798. [CrossRef]

2. Geyer, R.; Jambeck, J.R.; Law, K.L. Production, use, and fate of all plastics ever made. Sci. Adv. 2017, 3, e1700782. [CrossRef]

3. European Commission. EU Plastic Stratagy. Available online: https:/ / ec.europa.eu/commission/news/eu-plastics-strategy-20 18-nov-20_en (accessed on 9 January 2020).

4. $\quad$ Fakhouri, F.M.; Martelli, S.M.; Bertan, L.C.; Yamashita, F.; Mei, L.H.I.; Queiroz, F.P.C. Edible films made from blends of manioc starch and gelatin - Influence of different types of plasticizer and different levels of macromolecules on their properties. LWT 2012, 49, 149-154. [CrossRef]

5. Narancic, T.; Cerrone, F.; Beagan, N.; O'Connor, K.E. Recent Advances in Bioplastics: Application and Biodegradation. Polymers 2020, 12, 920. [CrossRef]

6. Narancic, T.; Verstichel, S.; Chaganti, S.R.; Morales-Gamez, L.; Kenny, S.T.; De Wilde, B.; Padamati, R.B.; O'Connor, K.E. Biodegradable Plastic Blends Create New Possibilities for End-of-Life Management of Plastics but They Are Not a Panacea for Plastic Pollution. Environ. Sci. Technol. 2018, 52, 10441-10452. [CrossRef]

7. Araújo, C.; Rodrigues, A.; Joele, M.P.; Araújo, E.; Lourenço, L. Optimizing process parameters to obtain a bioplastic using proteins from fish byproducts through the response surface methodology. Food Packag. Shelf Life 2018, 16, 23-30. [CrossRef]

8. Al Khawli, F.; Pateiro, M.; Domínguez, R.; Lorenzo, J.M.; Gullón, P.; Kousoulaki, K.; Ferrer, E.; Berrada, H.; Barba, F.J. Innovative Green Technologies of Intensification for Valorization of Seafood and Their By-Products. Mar. Drugs 2019, 17, 689. [CrossRef]

9. Wasswa, J.; Tang, J.; Gu, X. Utilization of Fish Processing By-Products in the Gelatin Industry. Food Rev. Int. 2007, 23, 159-174. [CrossRef]

10. Huang, T.; Tu, Z.-C.; Shangguan, X.-; Wang, H.; Zhang, L.; Sha, X.-M. Rheological and structural properties of fish scales gelatin: Effects of conventional and ultrasound-assisted extraction. Int. J. Food Prop. 2017, 1-11. [CrossRef]

11. Fakhouri, F.M.; Costa, D.; Yamashita, F.; Martelli, S.M.; Jesus, R.C.; Alganer, K.; Collares-Queiroz, F.P.; Innocentini-Mei, L.H. Comparative study of processing methods for starch/gelatin films. Carbohydr. Polym. 2013, 95, 681-689. [CrossRef] 
12. Podshivalov, A.; Zakharova, M.; Glazacheva, E.; Uspenskaya, M. Gelatin/potato starch edible biocomposite films: Correlation between morphology and physical properties. Carbohydr. Polym. 2017, 157, 1162-1172. [CrossRef]

13. Mrockzcowska, M.; CunhaNeves, A. Effects of different gelatin sources on characteristics of starch and gelatin blend bioplastic. Polimero 2019, 27. [CrossRef]

14. Eyre, C.; Casey, B.; Moyne, M.; Cunha Neves, A. BioPack Project: The Use of Concurrent Design in the Generation of Bioplastics with High Environmental Impact; Abstract of an Oral Presentation Presented at Environ; Institute of Technology Carlow: Carlow, Ireland, 2019.

15. Gontard, N.; Guilbert, S.; Cuq, J.-L. Edible Wheat Gluten Films: Influence of the Main Process Variables on Film Properties using Response Surface Methodology. J. Food Sci. 1992, 57, 190-195. [CrossRef]

16. Santana, R.F.; Bonomo, R.C.F.; Gandolfi, O.R.R.; Rodrigues, L.B.; Santos, L.S.; Pires, A.C.D.S.; De Oliveira, C.P.; Fontan, R.D.C.I.; Veloso, C.M. Characterization of starch-based bioplastics from jackfruit seed plasticized with glycerol. J. Food Sci. Technol. 2018, 55, 278-286. [CrossRef]

17. Neves, A.C.; Ming, T.; Mroczkowska, M.; Culliton, D. The Effect of Different Starches in the Environmental and Mechanical Properties of Starch Blended Bioplastics. Adv. Sci. Technol. Eng. Syst. J. 2020, 5, 550-554. [CrossRef]

18. Martelli, S.M.; Laurindo, J.B. Chicken Feather Keratin Films Plasticized with Polyethylene Glycol. Int. J. Polym. Mater. 2012, 61, 17-29. [CrossRef]

19. Falguera, V.; Quintero, J.P.; Jiménez, A.; Muñoz, J.A.; Ibarz, A. Edible films and coatings: Structures, active functions and trends in their use. Trends Food Sci. Technol. 2011, 22, 292-303. [CrossRef]

20. Kavoosi, G.; Dadfar, S.M.M.; Purfard, A.M. Mechanical, Physical, Antioxidant, and Antimicrobial Properties of Gelatin Films Incorporated with Thymol for Potential Use as Nano Wound Dressing. J. Food Sci. 2013, 78, E244-E250. [CrossRef]

21. Fakhouri, F.M.; Martelli, S.M.; Caon, T.; Velasco, J.I.; Mei, L.H.I. Edible films and coatings based on starch/gelatin: Film properties and effect of coatings on quality of refrigerated Red Crimson grapes. Postharvest Biol. Technol. 2015, 109, 57-64. [CrossRef]

22. Marichelvam, M.K.; Jawaid, M.; Asim, M. Corn and Rice Starch-Based Bio-Plastics as Alternative Packaging Materials. Fibers 2019, 7, 32. [CrossRef]

23. Amin, M.R.; Chowdhury, M.A.; Kowser, M.A. Characterization and Performance Analysis of Composite Bioplastics Synthesized Using Titanium Dioxide Nanoparticles with Corn Starch. Heliyon 2019, 5, e02009. [CrossRef]

24. Neves, A.C.; Moyne, M.M.; Eyre, C.; Casey, B.P. Acceptability and Societal Impact of the Introduction of Bioplastics as Novel Environmentally Friendly Packaging Materials in Ireland. Clean Technol. 2020, 2, 9. [CrossRef]

25. Basiak, E.; Lenart, A.; Debeaufort, F. Effect of starch type on the physico-chemical properties of edible films. Int. J. Biol. Macromol. 2017, 98, 348-356. [CrossRef] [PubMed]

26. Abdu, A.H.D.; Pudjirahar, S.; Karina, M.; Putri, O.D.; Fauziyyah, R.H. Fabrication and Characterization of Sweet Potato Starch-based Bioplastics Plasticized with Glycerol. J. Biol. Sci. 2018, 19, 57-64. [CrossRef]

27. Aznury, M. Mechanical Properties of Bioplastics Product from Musa Paradisica Formatypica Concentrate with Plasticizer Variables. J. Physics Conf. Ser. 2019, 1167, 012048. [CrossRef]

28. Fan, M.; Fu, F. Advanced High Strength Natural Fibre Composites in Construction; Woodhead Publishing: London, UK, 2017; pp. 59-83. Available online: https://www.sciencedirect.com/science/article/pii/B9780081004111000030 (accessed on 21 February 2021).

29. Larotonda, F.D.S.; Matsui, K.N.; Soldi, V.; Laurindo, J.B. Biodegradable films made from raw and acetylated cassava starch. Braz. Arch. Biol. Technol. 2004, 47, 477-484. [CrossRef]

30. Woggum, T.; Sirivongpaisal, P.; Wittaya, T. Properties and characteristics of dual-modified rice starch based biodegradable films. Int. J. Biol. Macromol. 2014, 67, 490-502. [CrossRef]

31. Matweb.com. Tensile Property Testing of Plastics. Available online: http://www.matweb.com/reference/tensilestrength.aspx (accessed on 25 September 2020).

32. Neves, A.; Harnedy, P.; O’Keeffe, M.; Alashi, M.; Aluko, R.; FitzGerald, R. Peptide identification in a salmon gelatin hydrolysate with antihypertensive, dipeptidyl peptidase IV inhibitory and antioxidant activities. Food Res. Int. 2017, 100, 112-120. [CrossRef] [PubMed] 